OPEN

SUBJECT AREAS:

MEDICAL RESEARCH

PAEDIATRIC RESEARCH

Received

14 February 2014

Accepted

11 August 2014

Published

26 September 2014

Correspondence and requests for materials should be addressed to

F.S.A.Z. (D_fl329@

hotmail.com)

\section{Altered ghrelin levels in boys with autism: a novel finding associated with hormonal dysregulation}

Felwah S. Al-Zaid ${ }^{1,2}$, AbdelFattah A. Alhader ${ }^{1}$ \& Laila Y. Al-Ayadhi ${ }^{1,2}$

'Department of Physiology, College of Medicine, Riyadh, Kingdom of Saudi Arabia, ${ }^{2}$ Autism Research and Treatment Center, AL-Amodi Autism Research Chair, College of Medicine, Riyadh, Kingdom of Saudi Arabia.

Autism is a neurodevelopmental disorder with unclear pathogenesis. Many clinical observations and hormone studies have suggested the involvement of the neuroprotective hormone ghrelin in autism. The current study aimed to investigate the potential role of ghrelin in autism and to elucidate the associated hormonal dysregulation. This case-control study investigated acyl ghrelin (AG), des-acyl ghrelin (DG), total testosterone (TT), free testosterone (FT), leptin and growth hormone (GH) levels in 31 male children with autism and 28 healthy age and sex-matched controls. Hormone levels were measured in the blood using enzyme-linked immunosorbent assay and chemiluminescence immunoassay kits. AG, DG and GH levels were significantly lower in the autism group than in the control group $(p \leq 0.001, p \leq 0.005$ and $p \leq 0.05$, respectively). However, TT, FT and leptin levels were significantly higher in the autism group than in the control group $(\mathrm{p} \leq \mathbf{0 . 0 5}, \mathrm{p} \leq \mathbf{0 . 0 0 1}$ and $\mathrm{p} \leq \mathbf{0 . 0 1}$, respectively). Our results for the first time demonstrate low AG and DG levels in autistic children. Considering the capacity of ghrelin to affect neuroinflammatory and apoptotic processes that are linked to autism, this study suggests a potential role for the hormone ghrelin in the pathogenesis of autism.

utism spectrum disorders (ASDs) are a group of heterogeneous neurodevelopmental disorders that are classified as pervasive developmental disorders. ASDs are usually characterised by clinical manifestations of delayed or abnormal language development, deficits in social interaction, repetitive behaviours and restricted interest $\mathrm{t}^{1}$. The pathogenesis of autism is not completely understood; however, a genetic origin has been recognised, and potential roles for both environmental factors and immune dysfunction have also been reported ${ }^{1}$. Hormonal dysregulation in autism remains a strong candidate, as a wide range of hormonal abnormalities have been identified in autistic children. This finding indicates the significant involvement of the hypothalamicpituitary-adrenal axis in the pathophysiology of the disease ${ }^{1}$.

A significant volume of scientific evidence suggests a possible role for the hormone ghrelin in autism. Ghrelin is a 28 -amino acid peptide that stimulates growth hormone $(\mathrm{GH})$ release from the anterior pituitary gland ${ }^{2}$. Ghrelin has a wide range of physiological functions, and it represents a molecular link between peripheral metabolism and brain cognition. The hippocampus, which is the main target of action for ghrelin in the central nervous system (CNS) and plays an important role in memory and learning ${ }^{3}$, is also affected in autism ${ }^{4}$. Moreover, ghrelin plays an important role in synaptogenesis, mainly in the hippocampal area ${ }^{5}$, and abnormal synaptogenesis in this area has been reported in autism ${ }^{6}$. Ghrelin has proliferative and anti-apoptotic effects in the CNS, especially during oxygen/glucose deprivation; thus, it may protect the hypothalamus against reactive oxygen species, which have recently been linked to autism ${ }^{7}$. In addition, ghrelin protects primary cortical neurons from apoptosis induced by glutamate, an amino acid that is elevated in autistic children .

Ghrelin influences the sleep-wake cycle, and its levels increase in the first hours of sleep in healthy individuals? Additionally, ghrelin is the most powerful orexigenic peptide and is known to suppress locomotor activity ${ }^{10}$. Sleep and appetite disturbances, and hyperactivity are among the frequent problems facing children with autism ${ }^{11}$. These observations, taken together, prompted us to hypothesise that ghrelin could be involved in the pathogenesis of autism. It wasn't clearly distinctive in the literature which of those actions mediated through AG and which were mediated through DG despite AG is considered generally the active form ${ }^{17}$.

Ghrelin cannot function in isolation from other hormones; for example, in many clinical settings, ghrelin plasma levels are negatively correlated with elevated plasma testosterone levels ${ }^{12}$, and pre-pubertal testosterone therapy has been shown to be associated with a significant decrease in circulating ghrelin levels in boys ${ }^{13}$. At the 
same time, androgens are implicated in the pathophysiology of autism, as hyper-androgenism has been reported in children with autism $^{11}$. This relationship suggests that ghrelin is prone to suppression by the elevated androgens in children with autism.

Similarly, the hormone leptin represents another potential link between ghrelin and autism, as these hormones have an inverse relationship ${ }^{14,15}$. Leptin inhibits ghrelin transcription in a dosedependent manner, thus reducing ghrelin levels ${ }^{16}$, and leptin levels have been reported to be significantly higher in children with autism $^{14}$. These elevated leptin levels may be associated with decreased ghrelin levels in autism.

However, ghrelin and GH are strongly connected, as ghrelin is known for its capacity to stimulate the release of $\mathrm{GH}^{17}$. Additionally, in an animal model of induced GH deficiency, gastric ghrelin mRNA levels and circulating ghrelin levels were significantly reduced, suggesting that ghrelin gene expression is influenced by GH status ${ }^{18}$.

In light of the above-mentioned findings, this study was conducted to elucidate the possible role of ghrelin in autism, which was accomplished by measuring plasma ghrelin levels in autistic boys and healthy age-matched controls. This study also aimed to further elucidate the associated hormonal dysregulation; thus, serum levels of androgens, leptin and GH were also measure.

\section{Methods}

Subject selection. This case-control study was conducted on 59 male children: 31 had classic-onset autism, and 28 were age- and sex-matched healthy control children. Their ages ranged from 3 to 8 years (mean $\pm \mathrm{SD}=5.59 \pm 2.26$ years). All of the boys included in the study were pre-pubertal (Tanner stage 1). Boys with autism were recruited from the Autism Research and Treatment Center, College of Medicine, King Saud University, Riyadh, Saudi Arabia. The study was limited to the male sex because of the lack of female patients. The patients in this study fulfilled the criteria for the diagnosis of autism according to the 4th edition of the Diagnostic and statistical Manual of Mental disorders (DSM4) (American Psychiatric association: Diagnostic and Statistical Manual of Mental Disorders, 4th ed. Washington DC: American Psychiatric Association, 1994.). ADOS (Autism Diagnostic Observation Schedule) and CARS (Childhood Autism Rating Scale) was performed to assign the diagnosis of autism according to DSM4. The patients included in this study had no associated neurological diseases (such as cerebral palsy or tuberous sclerosis) or metabolic disorders (e.g., phenylketonuria). None of the patients have intellectual disability.

Written consent was obtained from the parents according to the guidelines of the Institutional Review Board (IRB) of the College of Medicine, King Saud University, Riyadh, Saudi Arabia. The IRB approved the study protocol (approval no. E-10-341).

Anthropometric measurements. The height and weight of individuals in the autism and control groups were measured using an electronic scale. The occipito-frontal head circumference, waist circumference and hip circumference were measured using a meter. The body mass index (BMI) and waist to hip ratio $(\mathrm{W} / \mathrm{H})$ were calculated.

Biochemical assays. Venous blood samples $(7 \mathrm{~mL})$ were collected between 8:00 and 9:00 am after an overnight fast and were divided immediately as follows: a $3 \mathrm{~mL}$ aliquot of blood was dispensed into an EDTA tube containing $30 \mu \mathrm{L}$ of phydroxymercuribenzoic acid (PHMBA) to prevent the degradation of acyl ghrelin (AG). This sample was used to measure both AG and DG. A $4 \mathrm{~mL}$ aliquot of blood was dispensed into a plain plastic tube and was used to measure total testosterone (TT), free testosterone (FT), sex hormone-binding globulin (SHBG), leptin and baseline GH. The samples were centrifuged for $10 \mathrm{~min}$ at 3500 r.p.m. followed by the addition of $100 \mu \mathrm{L}$ of $1 \mathrm{~N} \mathrm{HCl}$ to the EDTA tube samples, which were further centrifuged for $5 \mathrm{~min}$ at 3500 r.p.m. The blood samples were immediately separated and stored at $-80^{\circ} \mathrm{C}$ until use in the assay, and they were not subjected to freeze/thaw cycles.

Plasma levels of AG and DG were measured using SPI-BIO enzyme-linked immunosorbent assay (ELISA) kits obtained from IBL International GMBH. Baseline serum levels of GH were measured using LIAISON ${ }^{\circledR}$ hGH chemiluminescence immunoassay kits obtained from Diasorin, USA. Serum leptin, TT, FT and SHBG levels were measured using DIAsource ELISA kits (Nivelles, Belgium). All sample measurements were performed in duplicate; thus, two kits per hormone were used.

Statistical analysis. The data were analysed using SPSS Pc+ statistical software (version 18.0). Normality was tested, and the normal distribution of the data was confirmed. The independent samples $t$ test was used to compare means between the autism and control groups. The correlation between different variables was determined using the Karl Pearson correlation coefficient. Statistical significance was defined as $\mathrm{p} \leq 0.05$.
Table 1 | Clinical characteristics of normal controls and subjects with autism

\begin{tabular}{lccl} 
Parameter & Control group $\mathrm{n}=28$ & Autism group $\mathrm{n}=31$ & $\mathrm{p}$-value \\
\hline Age $(\mathrm{months})$ & $65.3 \pm 2.8$ & $67.19 \pm 3.73$ & 0.68 \\
Weight $(\mathrm{kg})$ & $19.3 \pm 0.8$ & $22.7 \pm 1.4$ & $0.05^{*}$ \\
Height $(\mathrm{cm})$ & $112 \pm 1.4$ & $117.9 \pm 2.6$ & 0.06 \\
$\mathrm{BMl}\left(\mathrm{kg} / \mathrm{m}^{2}\right)$ & $15.3 \pm 0.4$ & $15.9 \pm 0.5$ & 0.28 \\
Waist circ. $(\mathrm{cm})$ & $52.1 \pm 1.1$ & $55.7 \pm 1.6$ & 0.06 \\
Hip circ. $(\mathrm{cm})$ & $59.4 \pm 1.1$ & $62.6 \pm 1.8$ & 0.14 \\
Waist/hip ratio & $0.88 \pm 0.01$ & $0.89 \pm 0.01$ & 0.22 \\
Head circ. $(\mathrm{cm})$ & $51.2 \pm 1.2$ & $51.7 \pm 2.3$ & 0.29 \\
\hline
\end{tabular}

Abbreviations: N, number; BMI, body mass index; Waist circ., waist circumference; Hip circ., hip circumference; Head circ., head circumference

The data are presented as the mean values \pm standard deviations.

* $\mathrm{p} \leq 0.05$ was considered statistically significant.

\section{Results}

Data for the anthropometric measurements and hormonal analysis are presented in Table 1, Table 2 and Table 3 as the mean values \pm standard deviation. As Table 1 shows, the only significant difference between the autistic group and the controls occurred in body weight, which was $18 \%$ higher in the autistic group than in the controls ( 22.7 \pm 7.9 vs. $19.3 \pm 4.1 \mathrm{~kg} ; \mathrm{p} \leq 0.05)$. The mean of body mass Index for children with autism falls between the $50^{\text {th }}$ and $75^{\text {th }}$ percentile which doesn't indicate obesity.

As Table 2 shows, AG levels were lower in the autistic group than in the controls $(116.7 \pm 50.3$ vs. $170.5 \pm 59.3 \mathrm{pg} / \mathrm{mL} ; \mathrm{p} \leq 0.001)$. Similarly, DG levels were also lower in autistic individuals compared to the controls $(214.4 \pm 80.5$ vs. $299.3 \pm 139.7 \mathrm{pg} / \mathrm{mL} ; \mathrm{p} \leq 0.005)$. In the autistic group, TT levels were higher than those in the controls $(20.1 \pm 17.4$ vs. $13.1 \pm 6.7 \mathrm{ng} / \mathrm{dL} ; \mathrm{p} \leq 0.05)$. Moreover, FT levels were higher in the autistic group than in the controls $(90.8 \pm 77.9 \mathrm{vs}$. $26.8 \pm 22.9 \mathrm{pg} / \mathrm{dL} ; \mathrm{p} \leq 0.001)$. However, there was no significant difference in SHBG levels between the autistic group and the controls $(106 \pm 42.4$ vs. $101.8 \pm 30.1 \mathrm{nmol} / \mathrm{L} ; \mathrm{p}=0.6)$. Leptin concentrations were higher in the autistic group compared to the control group (1.4 \pm 1.3 vs. $0.67 \pm 0.5 \mathrm{ng} / \mathrm{mL} ; \mathrm{p} \leq 0.01)$. In autistic children, $\mathrm{GH}$ levels were lower compared to the levels in the controls $(0.53 \pm 0.5$ vs. $1 \pm$ $1.2 \mathrm{ng} / \mathrm{mL} ; \mathrm{p} \leq 0.05)$.

Table 3 shows the hormone levels in a weight-matched group to exclude the effect of adiposity on ghrelin and leptin levels.

Correlation analysis. Correlation analyses between the measured hormones and different variables in the autism group were performed as follows:

Correlations of AG with different variables: AG had significant negative correlations with age $(\mathrm{r}=-0.48, \mathrm{p} \leq 0.007)$, weight $(\mathrm{r}=-0.35, \mathrm{p} \leq 0.05)$, BMI $(\mathrm{r}=-0.39, \mathrm{p} \leq 0.05)$, waist circumference $(r=-0.50, p \leq 0.01)$, hip circumference $(r=-0.36, p \leq 0.05)$

Table 2 | Mean values of measured hormones and SHBG levels in control and autism groups

\begin{tabular}{lccl} 
Hormone & Control group $\mathrm{n}=28$ & Autism group $\mathrm{n}=31$ & $\mathrm{p}$-value \\
\hline AG $(\mathrm{pg} / \mathrm{mL})$ & $170.5 \pm 59.3$ & $116.7 \pm 50.3$ & $0.001^{*}$ \\
DG $(\mathrm{pg} / \mathrm{mL})$ & $299.3 \pm 139.7$ & $214.4 \pm 80.5$ & $0.005^{*}$ \\
TT $(\mathrm{ng} / \mathrm{dL})$ & $13.1 \pm 6.7$ & $20.1 \pm 17.4$ & $0.05^{*}$ \\
FT $(\mathrm{pg} / \mathrm{dL})$ & $26.8 \pm 22.9$ & $90.8 \pm 77.9$ & $0.001^{*}$ \\
SHBG $(\mathrm{nmol} / \mathrm{litre})$ & $101.8 \pm 30.1$ & $106 \pm 42.4$ & 0.66 \\
Leptin $(\mathrm{ng} / \mathrm{mL})$ & $0.67 \pm 0.5$ & $1.4 \pm 1.3$ & $0.01^{*}$ \\
$\mathrm{GH}(\mathrm{ng} / \mathrm{mL})$ & $1 \pm 1.20$ & $0.53 \pm 0.5$ & $0.05^{*}$ \\
\hline
\end{tabular}

Abbreviations: AG, acyl ghrelin; DG, des-acyl ghrelin; TT, total testosterone; $F T$, free testosterone; SHBG, sex hormone-binding globulin; $G H$, growth hormone.

The data are presented as the mean values \pm standard deviations.

$* \mathrm{p} \leq 0.05$ was considered statistically significant. 


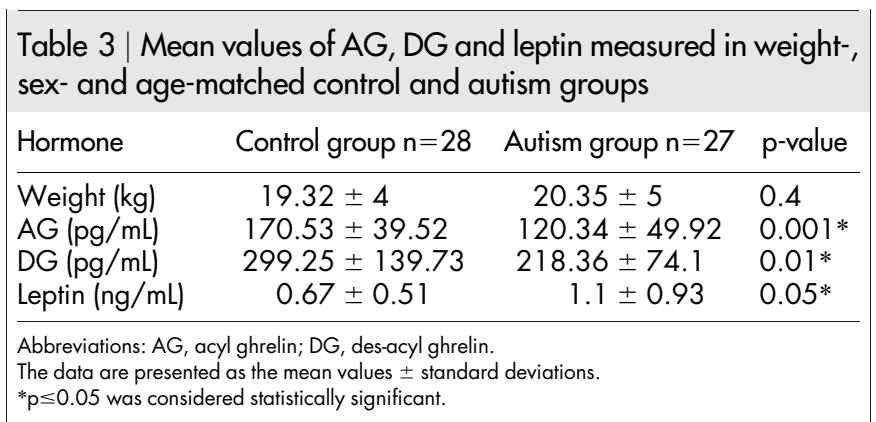

and $\mathrm{W} / \mathrm{H}$ ratio $(\mathrm{r}=-0.41, \mathrm{p} \leq 0.05)$. However, $\mathrm{AG}$ had a significant positive correlation with $\mathrm{DG}(\mathrm{r}=+0.59, \mathrm{p} \leq 0.001)$. No correlation between $A G$ and other hormones were found.

Correlations of DG with different variables: DG had significant negative correlations with age $(\mathrm{r}=-0.51, \mathrm{p} \leq 0.01)$, FT $(\mathrm{r}=-0.43$, $\mathrm{p} \leq 0.05)$ (Figure 1) and head circumference $(\mathrm{r}=-0.36, \mathrm{p} \leq 0.05)$.

Correlations of TT and FT with different variables: TT had significant positive correlations with FT $(\mathrm{r}=+0.7, \mathrm{p} \leq 0.001)$, age $(\mathrm{r}=+0.44, \mathrm{p} \leq 0.05)$, waist circumference $(\mathrm{r}=+0.37, \mathrm{p} \leq 0.05)$ and hip circumference $(\mathrm{r}=+0.37, \mathrm{p} \leq 0.05)$.

FT had significant positive correlations with height $(\mathrm{r}=+0.49$, $\mathrm{p} \leq 0.01)$, weight $(\mathrm{r}=+0.54, \mathrm{p} \leq 0.01)$, BMI $(\mathrm{r}=+0.40, \mathrm{p} \leq 0.05)$, waist circumference $(\mathrm{r}=+0.59, \mathrm{p} \leq 0.001)$, hip circumference $(\mathrm{r}=+0.52$, $\mathrm{p} \leq 0.01)$ and leptin level $(\mathrm{r}=+0.42, \mathrm{p} \leq 0.01)$.

Correlations of leptin with different variables: Leptin level had significant positive correlations with height $(\mathrm{r}=+0.53, \mathrm{p} \leq 0.01)$, weight $(r=+0.67, p \leq 0.001)$, BMI $(r=+0.56, p \leq 0.001)$, waist circumference $(\mathrm{r}=+0.61, \mathrm{p} \leq 0.001)$, hip circumference $(\mathrm{r}=+0.72$, $\mathrm{p} \leq 0.001)$ and head circumference $(\mathrm{r}=+0.43, \mathrm{p} \leq 0.02)$.

\section{Discussion}

Numerous hormone studies have been undertaken in children with autism; however, to our knowledge, this study is the first in which ghrelin was measured. Plasma levels of both AG and DG were significantly reduced in the autism group compared with healthy controls. This result can be attributed to local factors affecting ghrelin-secreting cells and to hormonal influences. Gastrointestinal (GIT) problems are frequent in autism, including dysbiosis, chronic GIT inflammation and chronic fungal, viral and bacterial infections $^{19}$. These disorders could affect the gastric mucosa and interfere with the normal function of ghrelin-secreting cells. Furthermore, ghrelin deficiency by itself can affect the gastric mucosa, as ghrelin is known for its role in maintaining mucosal health and integrity ${ }^{20}$. Thus, a loss of mucosal health and integrity could result in a further decrease in plasma ghrelin levels.

Alterations in plasma ghrelin levels may also be part of the extensive, well-studied hormonal dysregulation that characterizes autism, particularly the dysregulation of TT, FT, leptin and GH. In agreement with the findings of the current study, previous studies have shown that androgen levels are significantly higher in autism patients ${ }^{11}$. At the same time, it is well established that ghrelin plasma levels are negatively correlated with high plasma testosterone levels ${ }^{12}$. The current study confirms the negative correlation between FT and DG. This correlation may indicate that the reduced plasma level of ghrelin in autistic children is in part a consequence of suppression by elevated androgens.

Another hormone that has been studied in autism is leptin. Its relevance to ghrelin function comes from the observation that elevated plasma leptin levels are associated with reduced plasma ghrelin levels ${ }^{14,15}$. This finding is in agreement with the results of the current study, which revealed a significant elevation of leptin and a reduction of ghrelin levels in the autism group. In support of this notion, Komori et al. provided a novel molecular link between leptin and

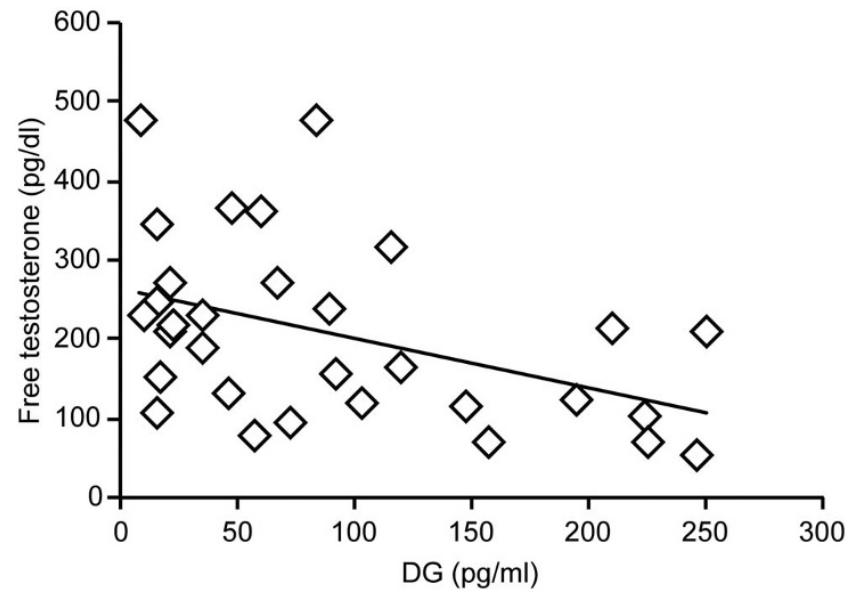

Figure 1 Correlation between DG and free testosterone in the autism group $(\mathrm{r}=-0.43, \mathrm{p} \leq 0.05)$.

ghrelin signaling, namely, the leptin-induced negative regulatory element-binding protein (NREBP), which suppresses ghrelin signalling $^{21}$. The high serum leptin levels in the current study is consistent with other studies that reported a significant elevation of leptin levels in autistic children ${ }^{14,22}$. The elevation of leptin levels can be explained in part by the observed significant elevation of androgen levels in autistic children. Both animal and human studies have shown that adipocytes have androgen receptors (ARs), and androgens are known to modulate the plasma leptin level ${ }^{23,24}$. Consistent with these reports, the current study revealed a significant positive correlation between leptin and FT. The significant elevation of leptin levels in autism may also be a consequence of the significant decrease in $\mathrm{GH}$ levels in autistic children, as will be discussed later.

Alterations in the levels of both ghrelin and leptin are known to be associated with adiposity ${ }^{25,26}$. As can be noted from the anthropometric data in the current study, the only significant difference between the autism and control groups was in body weight, which was significantly higher in the autism group. To exclude the effect of weight on the levels of these hormones, we excluded four children with high body weight from the autism group to create a group that was age-, sex- and weight-matched with the controls, as shown in Table 3. As presented in Table 3, there were significant reductions in both AG and DG plasma levels, with a significant increase in the plasma leptin level in the autism group compared with weight-matched controls.

It is intriguing the fact that children with autism have increased weight despite low ghrelin (an orexigenic hormone) and high leptin (an anorexigenic hormone) levels; this could be suggesting a drastic impairment in the central processing of such peripheral signals. Another possible explanation is the complexity through the involvement of many hormones other than ghrelin and leptin which might play role in affecting body weight.

In the present study, the significantly lower levels of both ghrelin and $\mathrm{GH}$ in autism are consistent with the unique relationship between these two hormones ${ }^{17}$. A genetic connection may also be present, as GH levels can affect ghrelin gene expression ${ }^{18}$ and, thus, can influence ghrelin plasma levels.

The present study revealed a significant negative correlation between DG and head circumference, which is similar to what was reported in children with Rett's syndrome ${ }^{27}$. This correlation implies that ghrelin may be involved in neurogenesis or neuroprotective effects in autism, as accelerated head circumference growth in the first year of life is considered as an early warning sign of autism in children ${ }^{28}$. Ghrelin is also known to play an important role in immune modulation in the CNS; in experimental autoimmune encephalomyelitis (EAE), ghrelin inhibits the production of the proinflammatory cytokines tumour necrosis factor-alpha (TNF- $\alpha$ ), 
interleukin-1 (IL-1) and IL-6, with microglia being the main target cells. Microglia are the main immunocompetent cells in the immature CNS and, in turn, can acquire various phenotypes that determine the CNS consequences of inflammation. It has been suggested that autism is a result of CNS derangements due to chronic inflammatory reactions ${ }^{29}$. This critical anti-inflammatory property of ghrelin indicates that it may serve as an anti-inflammatory agent for the control of human CNS disturbances triggered by the production of pro-inflammatory cytokines. Thus, the findings of the present study, which revealed significantly lower plasma ghrelin levels in autistic children, strongly suggest a potential role for ghrelin in the pathophysiology of autism.

However, the neuronal influence of leptin cannot be excluded, as leptin influences neurons by altering their structure and plasticity ${ }^{30}$. Furthermore, a role for leptin in brain development and maturation is suggested based on the capacity of leptin to regulate brain weight, brain protein content and several neuronal and glial markers ${ }^{31}$. The present study revealed a significant positive correlation between leptin and head circumference in the autism group, which could indicate a potential role for leptin in the pathogenesis of autism, as accelerated growth of head circumference in the first year of life is a known feature of autism ${ }^{22}$. Additionally, leptin replacement in leptin-deficient humans leads to gross changes in brain structure, including an increase in grey matter volume in several discrete areas of the brain and an increase in brain weight ${ }^{30}$. These results indicate that leptin has a direct effect on brain size and subsequently on head circumference ${ }^{30}$.

The relationship between leptin and GH is also illustrated by the finding that serum leptin levels were altered depending on $\mathrm{GH}$ status, predominantly as a result of changes in fat mass and distribution ${ }^{32}$. Leptin levels were reduced after GH replacement therapy, and this effect was thought to be secondary to reduction in fat mass ${ }^{32}$. In contrast, another study found that leptin levels were significantly increased after a single dose of GH and subsequently dropped below the baseline; this observation indicates that GH has a direct regulatory effect on leptin gene expression ${ }^{33}$. Furthermore, changes in leptin concentrations at 1 and 3 months after the beginning of $\mathrm{GH}$ replacement therapy in GH-deficient individuals were correlated with growth in the first year of treatment ${ }^{34}$. The high leptin levels and the low GH levels observed in the current study confirm these earlier observations.

The present study revealed significant lower GH levels in autistic children compared with controls. Although autistic children exhibited no physical features of GH deficiency, particularly with respect to anthropometric parameters, these findings do not rule out the involvement of $\mathrm{GH}$ deficiency for the following reasons: first, the role of GH is not limited to physical growth; second, the significantly elevated androgen levels in autistic children and their correlation with growth parameters, along with the known anabolic effects of androgens ${ }^{35}$, can compensate for the effects of GH deficiency on physical growth; and third, even if GH was deficient, the GH receptors of autistic children might have an increased sensitivity that masks the physical effects of GH deficiency. Additionally, GH deficiency in children is associated with obesity; subsequently, GH replacement increases lean body mass and reduces body fat content $^{36}$. Although only one study reported elevated GH levels in autistic children ${ }^{37}$, an earlier study conducted in $1989^{38}$ revealed that autistic children had a delayed response to $\mathrm{GH}$ stimulation via clonidine and L-dopa; thus, GH may still be deficient in autistic children. This delayed response can be explained by the dopaminergic deficits and the reduced adrenaline levels in autism ${ }^{38}$.

Findings related to the hormones measured in this study and the suggested hormonal inter-relationships are summarized in Figure 2.

The current study revealed significantly lower AG, DG and GH levels and significantly higher androgen and leptin levels in children with autism compared with age- and sex-matched healthy controls.

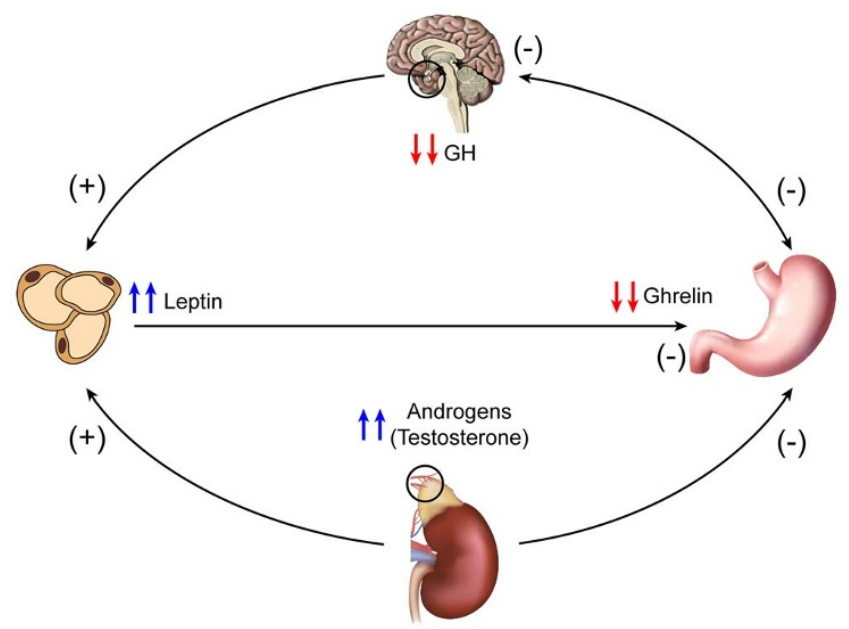

Figure $2 \mid$ The inter-relationship between the measured hormones in autism suggested by the current study (created by F.A-Z).

These hormones are inter-related, and they have direct effects on many clinical and pathological aspects of autism. The role of ghrelin in the pathophysiology of autism should be further studied at molecular levels as well as its implication in autism treatment. role of anti-androgen therapy in autism should also be investigated, as androgens function as the pace-maker for hormonal dysregulation. Correction of this dysregulation might have a direct influence on both ghrelin and leptin, which in turn affect GH levels. Investigations of the genetic bases for these phenomena should be conducted in future studies.

The main limitation of this study is the lack of female subjects with autism; thus, the study was limited to only the male sex. Additionally, the number of subjects included in the study was not large and was also limited by the availability of both autism patients and controls. However, in the opinion of the authors, this study contributes significantly to the understanding of hormonal dysregulation in the pathophysiology of autism, as it provides baseline data regarding hormonal profiles in autism and substantiates potential clinical interventions.

1. Levy, S. E., Mandell, D. S. \& Schultz, R. T. Autism. Lancet 374, 1627-1638 (2009).

2. Asakawa, A. et al. A role of ghrelin in neuroendocrine and behavioral responses to stress in mice. Neuroendocrinology 74, 143-147 (2001).

3. Sato, T., Fukue, Y., Teranishi, H., Yoshida, Y. \& Kojima, M. Molecular forms of hypothalamic ghrelin and its regulation by fasting and 2-deoxy-d-glucose administration. Endocrinology 146, 2510-2516 (2005).

4. DeLong, G. R. Autism, amnesia, hippocampus, and learning. Neurosci. Biobehav. Rev. 16, 63-70 (1992).

5. Diano, S. et al. Ghrelin controls hippocampal spine synapse density and memory performance. Nat. Neurosci. 9, 381-388 (2006).

6. Bourgeron, T. A synaptic trek to autism. Curr. Opin. Neurobiol. 19, 231-234 (2009).

7. Adams, J. et al. Nutritional and metabolic status of children with autism vs. neurotypical children, and the association with autism severity. Nutr. Metab. (Lond.) 8, 34 (2011).

8. Shimmura, C. et al. Alteration of plasma glutamate and glutamine levels in children with high-functioning autism. PLoS One 6, e25340 (2011).

9. Dzaja, A. et al. Sleep enhances nocturnal plasma ghrelin levels in healthy subjects. Am. J. Physiol. Endocrinol. Metab. 286, E963-E967 (2004).

10. Pfluger, P. T. et al. Simultaneous deletion of ghrelin and its receptor increases motor activity and energy expenditure. Am. J. Physiol. Gastrointest. Liver Physiol. 294, G610-G618 (2008).

11. Geier, D. A. \& Geier, M. R. A prospective assessment of androgen levels in patients with autistic spectrum disorders: biochemical underpinnings and suggested therapies. Neuro. Endocrinol. Lett. 28, 565-573 (2007).

12. Matsubara, M. et al. Estrogen modulates ghrelin expression in the female rat stomach. Peptides 25, 289-297 (2004).

13. Lebenthal, Y. et al. Effect of sex hormone administration on circulating ghrelin levels in peripubertal children. J. Clin. Endocrinol. Metab. 91, 328-331 (2006). 
14. Ashwood, P. et al. Brief report: plasma leptin levels are elevated in autism: association with early onset phenotype? J. Autism Dev. Disord. 38, 169-175 (2008).

15. Tschöp, M. et al. Circulating ghrelin levels are decreased in human obesity. Diabetes 50, 707-709 (2001).

16. Zhao, Z. et al. Gastric leptin, but not estrogen and somatostatin, contributes to the elevation of ghrelin mRNA expression level in fasted rats. J. Endocrinol. 196, 529-538 (2008).

17. Kojima, M. \& Kangawa, K. Ghrelin: structure and function. Physiol. Rev. 85, 495-522 (2005).

18. Caminos, J. E., Seoane, L. M., Tovar, S. A., Casanueva, F. F. \& Dieguez, C. Influence of thyroid status and growth hormone deficiency on ghrelin. Eur. J. Endocrinol. 147, 159-163 (2002).

19. Cubala-Kucharska, M. The review of most frequently occurring medical disorders related to aetiology of autism and the methods of treatment. Acta. Neurobiol. Exp. (Wars) 70, 141-146 (2010).

20. El Eter, E., Al Tuwaijiri, A., Hagar, A. \& Arafa, M. In vivo and in vitro antioxidant activity of ghrelin: attenuation of gastric ischemic injury in the rat. J. Gastroenterol. Hepatol. 22, 1791-1799 (2007).

21. Komori, T. et al. Regulation of ghrelin signaling by a leptin-induced gene, negative regulatory element-binding protein, in the hypothalamic neurons. J. Biol. Chem. 285, 37884-37894 (2010)

22. Blardi, P. et al. Variations of plasma leptin and adiponectin levels in autistic patients. Neurosci. Lett. 479, 54-57 (2010).

23. Sjogren, J., Li, M. \& Bjorntorp, P. Androgen hormone binding to adipose tissue in rats. Biochim. Biophys. Acta. 1244, 117-120 (1995).

24. Dieudonne, M. N., Pecquery, R., Boumediene, A., Leneveu, M. C. \& Giudicelli, Y. Androgen receptors in human preadipocytes and adipocytes: regional specificities and regulation by sex steroids. Am. J. Physiol. 274, C1645-C1652 (1998).

25. Bellone, S. et al. Acylated and unacylated ghrelin levels in normal weight and obese children: influence of puberty and relationship with insulin, leptin and adiponectin levels. J. Endocrinol. Invest. 35, 191-197 (2012).

26. Falorni, A. et al. Leptin serum levels in normal weight and obese children and adolescents: relationship with age, sex, pubertal development, body mass index and insulin. Int. J. Obes. Relat. Metab. Disord. 10, 881-890 (1997).

27. Haraa, M. et al. Ghrelin levels are reduced in Rett syndrome patients with eating difficulties. Int. J. Dev. Neurosci. 29, 899-902 (2011).

28. Dawson, G. et al. Rate of head growth decelerates and symptoms worsen in the second year of life in autism. Biol. Psychiatry. 61, 458-464 (2007).

29. Hagberg, H., Gressens, P. \& Mallard, C. Inflammation during fetal and neonatal life: implications for neurologic and neuropsychiatric disease in children and adults. Ann. Neurol. 71, 444-457 (2012).

30. Matochik, J. A. et al. Effect of leptin replacement on brain structure in genetically leptin-deficient adults. J. Clin. Endocrinol. Metab. 90, 2851-2854 (2005).

31. Pomerants, T., Tillmann, V., Jürimäe, J. \& Jürimäe, T. Relationship between ghrelin and anthropometrical, body composition parameters and testosterone levels in boys at different stages of puberty. J. Endocrinol. Invest. 29, 962-967 (2006).

32. Matsuoka, H. et al. Changes in body composition and leptin levels during growth hormone $(\mathrm{GH})$ treatment in short children with various $\mathrm{GH}$ secretory capacities. Euro. J. Endo. 140, 35-42 (1999).
33. Lissett, C., Clayton, P. \& Shalet, S. The acute leptin response to GH. J. Clin Endocrinol. Metab. 86, 4412-4415 (2001).

34. Kristrom, B., Carlsson, B., Rosberg, S., Carlsson, L. M. \& Albertsson-Wikland, K. Short-term changes in serum leptin levels provide a strong metabolic marker for the growth response to growth hormone treatment in children. Swedish Study Group for Growth Hormone Treatment. J Clin. Endocrinol. Metab. 83, 2735-2741 (1998).

35. Moorthy, B., Papadopolou, M., Shaw, D. G. \& Grant, D. B. Depot testosterone in boys with anorchia or gonadotrophin deficiency: effect on growth rate and adult height. Arch. Dis. Child. 66, 197-199 (1991).

36. Drake, W. M., Howell, S. J., Monson, J. P. \& Salet, S. M. Optimizing GH therapy in adults and children. Endocr. Rev. 22, 425-450 (2001).

37. Iwata, K. et al. Investigation of the serum levels of anterior pituitary hormones in male children with autism. Mol. Autism 2, 16 (2011).

38. Ragusa, L., Maurizio, E. \& Scifto, R. Growth hormone deficit in autism. J. Autism Dev. Disord. 23, 421-422 (1993).

\section{Acknowledgments}

We give special thanks to the Autism Research and Treatment Center and the Al-Amoud Chair for Autism Research at King Khalid Hospital, King Saud University, Riyadh, Saudi Arabia; King Abdul Aziz City for Science and Technology (KACST); and the National Plan for Science and Technology (NPST) at King Saud University for providing this work with the necessary funds. We would also like to thank Mr. James Chu, Mrs. Evelyn Donguines, Mr. Sahipa Sabirin, Mr. Rajeh Al-Mutairi and the central lab at KKHU for their much-appreciated support during the laboratory portion of this work. We would like to give very special thanks to Professor Abduljaleel Abdulgader, the head of higher studies in the Physiology Department, King Saud University, Riyadh, Saudi Arabia, for his much-appreciated support and guidance.

\section{Author contributions}

F.A.-Z. and A.A. contributed equally to the study design, methodology and statistics. F.A.-Z. wrote the main manuscript text and prepared the figures $(1,2)$. L.A.-A. reviewed the study design and methodology. All authors reviewed the manuscript.

\section{Additional information}

Competing financial interests: The authors declare no competing financial interests.

How to cite this article: Al-Zaid, F.S., Alhader, A.A. \& Al-Ayadhi, L.Y. Altered ghrelin levels in boys with autism: a novel finding associated with hormonal dysregulation. Sci. Rep. 4, 6478; DOI:10.1038/srep06478 (2014).

This work is licensed under a Creative Commons Attribution-NonCommercialNoDerivs 4.0 International License. The images or other third party material in this article are included in the article's Creative Commons license, unless indicated otherwise in the credit line; if the material is not included under the Creative Commons license, users will need to obtain permission from the license holder in order to reproduce the material. To view a copy of this license, visit http:// creativecommons.org/licenses/by-nc-nd/4.0/ 